\title{
"Community" as a Reference for American Minority Groups: A Theory of Unintended Negative Consequences
}

\author{
Lisa Fisher \\ College of Wooster, Wooster, Ohio, USA \\ Email: lfisher@wooster.edu
}

How to cite this paper: Fisher, L. (2017) "Community" as a Reference for American Minority Groups: A Theory of Unintended Negative Consequences. Open Journal of Social Sciences, 5, 224-237. https://doi.org/10.4236/jss.2017.56020

Received: May 24, 2017

Accepted: June 19, 2017

Published: June 22, 2017

Copyright $\odot 2017$ by author and Scientific Research Publishing Inc. This work is licensed under the Creative Commons Attribution International License (CC BY 4.0).

http://creativecommons.org/licenses/by/4.0/

\section{(c) (i) Open Access}

\begin{abstract}
The phrase "the community" is commonly used in naming minority groups in the US, for example, the African American community or the Muslim community. The phrase carries some benefits in terms of voice, sentiment, solidarity and empowerment, and it is widely accepted as a respectful reference. However, I argue that its use and meaning also carry unintended negative social psychological implications for how some minority group members may view themselves within the larger society and how some non-minority group members may view persons who identify as members of minority groups. In this paper, I examine the meaning and entailments of the word "community" as a convention of naming. I argue that negative implications stem from ubiquitous discursive emphasis on in-group sameness and groupness, which are rooted in historical practices of distillation and homogenization of diverse groups and demonstrate and invite perpetuation of stereotypes and prejudices, reinforce insider/outsider divides, and detract from personhood and social integration.
\end{abstract}

\section{Keywords}

Community, American Minority Groups, Homogenization, Social Psychology

\section{Introduction}

The word community is commonly used in naming minority groups in the US. A famous example of this is when the Rev. Dr. Martin Luther King, Jr., referred to "the Negro community" in his "I Have a Dream" speech in 1963 [1]. Today, this same convention is often applied broadly when referring to all American minority groups. It is common to hear references such as the African American community, the Hispanic community, the American Indian community, the Arab community, the transgender community, the gay community, and the Jew- 
ish community, and the popularity of this convention appears to be growing.

We see the phrase the community, with any one of a number of minority group names inserted in the blank space, increasingly popping up everywhere. A Google search using the words "the transgender community", for example, turns up over 56,000,000 results including activist and advocacy sites, media reports and blogs. A search using the words "the African American community", turns up about 132,000,000 results ranging from advocacy sites to reports on health and education to White House publications. YouTube videos, newspaper articles and the websites of community service organizations evidence the ubiquitous use of the phrase the community to refer to minority populations.

We rarely hear the phrase the community used to refer to the perspectives and interests of non-minority populations. The phrase may be used to discuss the activities of groups who share common practices, such as the arts community, the business community, or the medical community. In addition, the phrase is used to refer to a geographic location where individuals live or work, such as a neighborhood in a metropolitan area. However, when the community is used to refer to any minority group, the reference is much more general, less likely to be tied to a geographic location, and, in many ways, has come to signify "marginalized group". To be clear, I am not positing that the adoption of the phrase the community is causing marginalization or that the use of the word community itself automatically signals marginalization for all groups. I am interested in the increasing popularity of the phrase to refer to minority groups who have experienced marginalization due to social class, race, ethnicity, nationality, gender, sexuality, age, ability, religion or any other statuses.

Although the use of the community in this way is often associated with cultural competence and sensitivity, most people who employ the phrase do not critically evaluate its meaning and implications. This led me to ask: why does this phrase resonate so broadly, and what implications does it carry for social perceptions, minority/non-minority relations and inclusivity in American society?

I argue that the use of the phrase the community to refer to minority groups acts a mechanism to subtly perpetuate persistent stereotypes, prejudices and marginalization. This stems from long-standing, deeply-rooted, prejudicial assumptions about American minorities' in-group homogeneity and the corresponding practices of categorizing and separating so that, in line with stereotypes and prejudices, the identities and experiences of minority groups can be distilled into distinct, unidimensional, static classifications. It also stems from the propensity to overwhelmingly focus on the cohesiveness and social support aspects of community and overlook in-group diversity as well as relationships between marginalized and privileged statuses.

This article is neither an empirical piece nor an in-depth theoretical intervention. Rather, it is a critical essay within which I apply and integrate the empirical knowledge and theoretical tools of social science to offer an analysis and interpretation of meaning, context and implications. In the sections to follow, I 
briefly review key sociological theory relating to the study of community and examine the meaning of the word as it is commonly applied to American minority groups. I then examine that meaning within the context of historical homogenization of minority group members and experiences in the US, and I advance a theory of unintended negative social psychological implications of the use of the phrase the community for people who identify as part of minority groups and people who do not.

\section{The Meaning of Community}

When the Rev. Dr. King used the word community in Civil Rights Era America, it was critical that African Americans demonstrate solidarity as a means to social integration and personhood long denied them [1] [2] [3]. Solidarity remains important for each American minority group today in that it amplifies voice and provides refuge for members who face marginalization within the larger society. However, the meaning of community extends beyond notions of solidarity, and it is that larger meaning with which we must grapple if we are to consider the social implications of the widespread use of the phrase the community to refer to marginalized groups in contemporary America.

Studies of community have a long history in the social sciences, with some of the most influential emerging in the late $19^{\text {th }}$ century. Sociological scholars such as Toennies [4] and Durkheim [5] sought to understand the social experiences and implications of people living in smaller vs. larger configurations, which became a focus during the Industrial Revolution. Toennies' seminal concept of gemeinschaft holds that smaller communities tend to be cohesive, connected and familiar (in comparison to gesellschaft, the larger society). Durkheim's notion of mechanical solidarity echoed this, holding that smaller units of people, or communities, were automatically bonded by their in-group similarities [5] [6].

These classical theories, particularly that of Toennies, have been criticized as romanticized. Toennies did not account for inequalities, diverse interests, power struggles [7] or ways that hegemonic influences flow from privileged groups to impact marginalized groups [8]. Despite these criticisms and lingering arguments that the concept of community is not well-defined [6] [9] [10], the word continues to be strongly and emotionally associated with foundational cohesive relationships that make up the basis for human social life [6] [11], community sentiment [12] [13], and positive group identity [2] [3].

It is because of these strong associations that the word community is regularly used without much explanation. People generally assume that everyone knows what it means [6]. As the phrase the community has come into more popular use, these assumptions have seemingly remained. Yet the ubiquitous use of this word to refer to marginalized groups; the impact of the connotations of cohesiveness, connectedness and familiarity; and the implications for social relations have received little scholarly attention.

In my research, I've come across many examples of groups and organizations employing the phrase the community to refer to marginalized groups, 
which is what prompted me to write this article. However, my goal is not to "call out" groups and organizations using this reference but rather to draw attention to its widespread use in American public discourse and critically consider its impact.

To achieve this, I examine the meaning of the word community in the context of contemporary American society. This task stands at the juncture of sociology, social psychology and rhetorical criticism. Sociology contributes an understanding of contemporary minority group subjugation as well as its historical roots; social psychology contributes a focus on naming, language and sense-making as interactional processes that are contextual and socially constructed; and rhetorical criticism allows us to examine meaning, intent and the effects of language [14].

Words and meaning are key here. Words can be unifying, divisive, marginalizing, empowering, helpful, hurtful and many other things. The words we use matter. They matter in the ways we write our laws and policies. They matter in the ways we speak to each other and teach children about the world. Words are important indicators of meaning, values and assumptions in a society. Words carry important implications for how we think and act individually and collectively. Although at times the social impact of language is taken for granted, it is not simply a matter of semantics.

Attending to words is a matter of social and rhetorical construction. As Zerubavel [15] states, citing earlier work by Burke [16], “...(T)he word define derives from the Latin word for boundary...To define something is to mark its boundaries, to surround it with a mental fence that separates it from everything else...These lines play a critical role in the construction of social reality...Examining how we draw them is therefore critical to any effort to understand our social order" (p. 12).

While social categorizing is considered a fundamental human activity [15], it is important to recognize that this process is socially-constructed rather than objective. According to Sandstrom, Martin, Lively and Fine [17], conventions of language guide how we define and act toward people, objects and experiences in our environment, and we "...learn to see and respond to symbolically mediated realities...(that) are socially constructed" (p. 11). In this way, the use of the phrase the __ community to refer to marginalized groups is a "mental fence", to use Burke's [16] words, and that fence surrounds socially-constructed, commonly held assumptions about the nature of communityin American society.

Merriam-Webster Online Dictionary [18] provides what are referred to as simple and full definitions of the word community. The simple definition is "a group of people who live in the same area (such as a city, town, or neighborhood); a group of people who have the same interests, religion, race, etc.; a group of nations". The full definition expands on that to include "a unified body of individuals...the people with common interests living in a particular area... an interacting population of various kinds of individuals (as species) in a common location.... group of people with a common characteristic or interest living to- 
gether within a larger society"

(http://www.merriam-webster.com/dictionary/community). The denotative focus on unification, common interests and common location signify the ways that people understand the word community, which is based on the social process of naming.

From a social psychological perspective, naming is a convention within language that entails classifying and assigning meaning. Once naming occurs, the meaning of the name shapes perceptions and influences all future interactions that rely on that meaning. Naming is central to human beings' ability to think, make associations and consider means of action. Naming also structures emotion and feelings about people, objects, places and ideas. As Sandstrom, Martin, Lively \& Fine [17] put it, "The name organizes our perceptions and serves as a basis for subsequent behavior; that is, it intervenes between the 'stimulus' provided by the object and our 'response' to it. In other words, we respond to the name that we give...” (p. 63) and the meaning and entailments, or logical results, associated with that meaning.

Although the dividing lines and classifications that distinguish social groups are not always clean and precise, given the complexities of identity, the meaning and entailments of the community suggest a very cleanly erected "mental fence". Internal to this mental fence are "insiders", and external to it are "outsiders". Based on the denotative and connotative meaning associated with the name the community, the phrase implies a singular group of "insiders" with common interests and identities that possess a primary, overarching, unifying perspective and have a degree of familiarity and even warmth with one another, suggesting psychological proximity. Physical proximity is also implied, given the common association of the term community with shared geographic space. Connotations of psychological and physical proximity, groupness and sameness function to "standardize" members of the community. Because the phrase the community is so frequently attached when naming marginalized groups and members of American society hear it so ubiquitously, the meaning and entailments of community reflect and remain central to the ways that many people understand and think about minority group status. These processes are neither random nor objective but are fueled by ideologies of homogenization.

\section{Homogenization}

The United States has a long history of homogenization of racial and ethnic groups stemming from the colonial period that we carry forward today [19] [20]. The ways in which the phrase the community is used so broadly to refer to marginalized groups both reflect and perpetuate reliance on stereotypes and prejudicial notions present in American society that are deeply rooted in the legacy of homogenization. The connotations of the community as cohesive, connected and familiar represent a subtle mechanism by which marginalized groups are presented as distilled, unidimensional, static entities. We see some of 
the strongest evidence of this in the common language conventions that are often used formally and informally to categorize racial groups.

The racial category of "Native American" or "American Indian" demonstrates this point. The term did not exist among the indigenous peoples of what would be the Americas prior to Europeans assigning that name. As Desmond and Emirbayer [20] describe it: "Native American' flattens out the immensely different histories, languages, traditional beliefs, and rich cultural practices of various indigenous tribes...transform(ing) the multitude of indigenous people into one single category of people" (p. 15).

The transformation of groups into simplified categories both exhibits and facilitates marginalization. As Callero [21] writes, “(p)ower matters in the classification process. With greater power comes greater authority to establish the criteria for personhood" (p. 41). The funneling into categories is itself an act of power exercised by those with the authority to define and demarcate social boundaries, which in the US has historically been persons exhibiting white skin, masculinity, heterosexuality and Christianity. Consistently, this type of transformation of social groups has been linked to marginalization [20] [21] as those who identify as part of a simplified category are devalued and their personhood denied in favor of assigning groupness. According to Callero [21], while "(h)istorical circumstances and social categories are different,...the fundamental social processes at work are the same-and in the end, the destructive consequences are dreadfully similar" (p. 36).

Although the most visible roots of homogenization in the US pertain to race and ethnicity, the expanded use of the phrase the community to refer to all historically and contemporarily marginalized groups suggests not only continued but expanded adherence to homogenization. Not only does the categorization emphasize sameness and groupness applied to the individuals who identify as part of a minority group, but the exact same categorization is applied to all minority groups in one blanket language convention: the community. However, because of the general acceptance of community as a respectful term associated with positive sentiment, this is not typically interpreted as a bad thing, particularly in the short term.

Within the frame of homogenization, marginalized groups are likely to experience groupness within the ___ community as positive. Facing continued subjugation by the larger society, marginalized groups experience groupness as safer, insulating and empowering. It is well-established in sociology that ethnic groups (we can expand this to think about minority groups in general) who experience disconfirming rejection and social barriers within a society tend to turn inward to the safety of an in-group to meet normal human needs for validation and support. When one is part of a community, one is not alone and has in-group support for claiming identities and participating in culture. There is comfort and power in solidarity. There are also benefits, as the aforementioned literature shows, associated with sentiment, shared interests, and positive group identity. However, the reason the phrase the community appears to reso- 
nate so broadly is that its utility extends beyond these aspects.

The phrase appears to serve dual purposes. The phrase the community can be employed by people who identify as part of and/or wish to demonstrate cultural sensitivity toward marginalized groups. However, it can also be employed by people who adhere to essentialist notions about marginalized groups and engage in victim-blaming [22].

For example, a person discussing a decrease in the high school graduation rate of a group of ethnic minority students nationwide may say, "The (ethnic group name) community needs to address that problem". Because the phrase the community is so widely accepted as a respectful go-to reference, the person uttering it in the example above may believe they are "covering their bases", so to speak, and using a phrase that is politically correct. However, the reference is not culturally sensitive but reflects and resonates with persistent stereotypes and essentialist notions rooted in the legacy of homogenization, namely that the community is a single, unidimensional group and that poor performance by some members of a minority group results from group-level lack of effort, lack of ability, lack of responsibility, and lack of respect for "mainstream" cultural values. Thus, the implication here is that responsibility for this social problem rests with the community as a unidimensional entity that is mentally "fenced off" from the rest of American society. The fact that the phrase the community can be employed in ways that meet these dual purposes, as illustrated above, may help to explain its widespread use and application across American society as well as the reasons why the phrase is problematic.

\section{A Theory of Unintended Negative Consequences: Distillation and Disparate Meaning}

Unintended negative consequences of the use of phrase the community to refer to marginalized groups may stem from the convergence of the factors I have discussed thus far: popular understanding of community as sentiment, the institutionalized forces of essentializing and homogenization, and the power of language in influencing perception and interpretation. Together, these factors lend to highly distilled, highly consistent and seemingly highly compelling messages about the community. The meanings associated with the word community and the practices of referring to entire minority groups as singular communities originate and are perpetuated within the larger context of homogenization and marginalization. The dual purposes that can be served by the phrase the community allow people to talk past each other even when seemingly using the same naming convention. When this happens, within the social context of distillation of messages about minority groups, disparate meanings may go unnoticed as people focus on the popular understandings of community and, as Bruhn [6] found in his research, assume that everyone is operating with a common definition. Distillation and disparate meaning negatively impact those who identify as part of minority groups and those who do not.

In the section that follows, I theorize about negative effects that emerge from 
distillation and disparate meaning pathways. For minority groups, I focus on the ways that members, influenced social psychologically by the language of community and accustomed to being referred to as a single community within the context of homogenization, may perceive their relationship with the larger society. For non-minority groups, I focus on the ways that members, influenced social psychologically by the language of community and the persistent focus on minority groupness, may perceive minority groups.

Central to this is the consistent emphasis on groupness and sameness among "insiders" to the community that lends to both non-minority and minority group members perceiving an "us" and "them" dichotomy, thus perpetuating in-group/out-group divides. In the minds of some non-minority group members, the emphasis on sameness among members of the community seems to validate persistent stereotypes and prejudices already active in society, perpetuating ideas that the identity of the community is the default for all individuals who identify as part of it. In the minds of some minority group members, the emphasis on sameness seems to support the value of, and indeed the need for, turning inward to the community. These notions of "us" and "them" not only have the capacity to impact perceptions but the ways in which new information about the community is interpreted.

Selective attention to characteristics of sameness and groupness and the discounting or disregarding of evidence of diversity is likely to occur. Allport and Postman's [23] classic experiment about the content and transmission of rumors can be applied to illustrate the social psychological processes through which human beings selectively attend to information and settle on details that mesh with what they already believe. This theory is useful here because it brings focus to ways that the social construction of meaning is shaped by humans selectively attending to, interpreting and sharing information.

Allport and Postman [23] said that, as information is shared, three processes occur: leveling, sharpening and assimilation. Leveling occurs when some details are dropped from the story being told. Sharpening occurs when other details are highlighted, and assimilation occurs when details are altered to fit the teller's preconceived notions and biases and assist them in making sense of information and situations [17]. These processes function to distill information. This distillation often occurs tacitly as people listen to information and attempt to make sense of it by recalling what they already know or think about it. While these processes occur in specific contexts of interaction, given the prevalence of stereotypes and prejudices against minority groups in American society, information about the community is likely to be distilled accordingly on a much larger scale.

This selective focus also draws attention to the ways that the perspectives and interests of "insiders" are different from those of "outsiders". Rather than functioning to build awareness about issues and problems that systematically affect entire minority groups in American society, within the framework of communi$t y$, information about the perspectives and interests of "insiders" to the commu- 
nity is likely to be interpreted as applying to a unidimensional, isolated group. Those outside of the community are likely to view the issues and problems as arising within and therefore the responsibility of the community, disconnected from the larger society.

The processes of leveling, sharpening and assimilation [23] come into play again as minority group and non-minority group members alike seek to explain groupness, leading to focus on aspects of difference and separateness. Minority group members may engage in defensive othering [24] and turn inward to the solidarity of the group to define their marginalized status in opposition to oppressive and implicit othering [24] encountered in the larger society. Given the ubiquity of messages emphasizing sameness among members of the community and difference between the community and outsiders, evidence of the groupness of the community continues to accumulate.

Through this process, the community is placed in contrast to the presence and voices (plural) of anyone outside of it. As a result, members of the community may increasingly view themselves as standing together, isolated from, and placed in relief against the backdrop of the larger society. This further supports the internalization of notions of identity primarily associated with groupness.

Previous studies suggest that when these symbolic divisions exist, one means by which marginalized groups respond is through the reactive adoption of oppositional identities, which demonstrate the rejection of the norms of the larger society [20] [25]-[31]. Oppositional identities are problematic not because they are expressions of self and claiming group cultural affiliation but because they often directly undermine the ability of entire groups of people to achieve personhood due to the ways that these identities are interpreted within the framework of homogenization and marginalization. Non-minority group members, who themselves enjoy the privilege of claiming personhood over groupness, note the opposition to the larger society and the turning inward and, based on the "mental fence" associated with the community, reason that this is just further evidence validating groupness and sameness. We may think that our own personal capacity for thought and understanding could never be so limited; however, we all rely on these means of sense-making.

Human beings rely on common meaning, entailments, leveling, sharpening and assimilation on a daily basis. These serve as short-cuts for interpretation, are active even when we do not realize it, and affect our interpretation regardless of group affiliation. But the problem is not the use of short-cuts for sense-making purposes per se; it is the ways that the context of homogenization and marginalization affects these processes.

The more ubiquitous and consistent the messages about the community, the more likely people are to distill information in line with common meaning. Likewise, the more people are exposed to distilled information, the more they see fit to rely on those particular short-cuts for interpretation. The more they rely on those short-cuts, the less obvious the shortcuts become and the more likely 
it is that people across groups will come to accept the information yielded as common sense "truth" about the community. When information is regarded as common sense "truth", it is less likely to be critically evaluated in terms of the source of its meaning and historical roots, which lends to continued invisibility and incredible power in shaping human thought and action. These are the very processes which continue to drive implicit bias.

Although the interpretation process is largely invisible, the outcomes of it are indeed visible. Examples of this lie in the common ways that some non-minority group members interpret circumstances that disproportionately negatively affect minority groups in American society. Physical/residential segregation and socio-economic status are two outcomes that help to illustrate this point. Both are commonly relied upon as indicators of group marginalization, and both regularly enter into public discourse about minority groups in the US.

Starting with the example of segregation, it is common to hear non-minority group members interpret this phenomenon as "self-segregation". This selectively emphasizes and demonstrates belief in collective and, indeed, community-based choice and agency of minority groups in separating from the larger society. This selective emphasis stands in contrast to empirical findings that suggest separation is a self-protective reaction, often to social exclusion and limited social mobility [32] [33] [34]. The "self-segregation" interpretation is rooted in and validates notions of groupness and sameness among members of the community.

The common interpretation of differential socio-economic status, whether that is to explain better than average or worse than average outcomes, also illustrates this point. Variation in socio-economic status is often (mis)interpreted as evidence of inherent differences in effort, abilities, responsibility and values between the community and those outside of it. Non-minority interpretation, again based on the meanings associated with community and consistent messages homogenizing persons and groups with minority status, is commonly framed by a focus on collective and, indeed, community-based agency and choice of minority groups to either heighten or reduce participation in social institutions such as education and the labor market.

The fallacy of undifferentiating difference comes into play here, as the diverse histories and experiences of minority groups are "flattened", as Desmond and Emirbayer [20] (p. 326) describe, for ready comparison. When outcomes are better than average, this is chalked up to heightened desire or capacity among members of the community. When outcomes are worse than average, this is chalked up to a lack of desire or capacity among members of the community, often without taking into account differences in histories, resources and opportunities [35] [36]. These interpretations are rooted in and appear to validate notions of groupness and sameness among members of the community.

The unintended negative consequences that I posit here suggest that the phrase the community has considerable negative implications directly linked to historical patterns of homogenization and marginalization. The negative implications take on heightened importance as they mark the extreme social 
psychological subtleties of distilling, marginalizing and exclusionary language and undergird just how difficult these things can be to detect.

\section{Conclusions}

In this paper, I argue that the use of the phrase the community to refer to American minority groups perpetuates marginalization and negatively impacts the perceptions of minority and non-minority group members based on popular understanding of community as sentiment, institutionalized forces of essentializing and homogenization, and the power of language in influencing perception and interpretation. I advance a theory of distillation and disparate meaning to explain how these forces converge to bring about unintended negative consequences.

Given the emphasis on groupness and sameness and the ways that these notions comport with existing stereotypes and prejudices in ways that may seem, to the uncritical observer/participant, to lend credence to those stereotypes and prejudices, I argue that we should refrain from referring to any minority group as the community. At the very least, we should use the plural, communities. While this is a subtle difference, it quickly alleviates the problematic aspects of unidimensional sameness and groupness and allows some boundary-blurring [30], which, as I have argued here, begins with naming and assigning meaning. However, this change to the plural alone does not solve the problems of meaning and social understanding associated with such heavy and ubiquitous reliance on the phrase the community to refer to and consider the experiences of marginalized groups.

Homogenization as the community occurs, first and foremost, because of deep-seated ideas about the inherent superiority and inherent inferiority of social groups. But it continues, in large part, because it is normalized within our daily interactions in the "myriad of local settings" [24] (p. 440) that comprise our social institutions.

While critics may argue that this essay is about "semantics" that simply do not matter in the larger scheme of things, I counter with this: the larger scheme of things depends entirely on how we name and associate meaning. The mechanisms and processes by which social exclusion and marginalization persist are indeed rooted in language. In and through the processes of collective sense-making, the groupness of the community is confirmed, homogenization seemingly validated, and disparate meaning and social exclusion perpetuated. Given that naming and meaning are so often tied to and rooted in the past, long-standing and largely taken-for-granted, it is even more critical that we draw attention to them.

Examining the word community and the phrase the community as I have here, several things come into focus that underscore the significance of this research. We see the calcified roots of our historical adherence to ideologies of homogenization and marginalization that have brought us where we are today. We also see greater attention to identity validation and social justice that have 
influenced the adoption of language intended to be more respectful to historically marginalized social groups. However, even this is framed and limited by ideologies of homogenization and, as I have shown, can be employed in ways that resonate with those who wish to assert the atomistic agency of minority groups and blame the victim for social problems endured [22]. Further, even now, at a time of greater voice being claimed and actions taken by marginalized groups and their allies in concert with greater awareness of social justice that is mobilizing more people across social groups in advocacy and activism, we may still be prone to missing these important semantic cues in language. The language of the community and the meanings associated with it may blur into the background of daily experiences, but its meanings and implications are extraordinarily powerful and carry far-reaching implications for American society as a whole.

Although this article may succeed in encouraging critical questioning of the phrase the community as a taken-for-granted convention of language, the work is limited in that I examine only a segment of the available literature. Future research should consider this theory of unintended negative consequences alongside other empirical data.

There is a continued need to examine how marginalizing language, no matter how subtle, is impactful. Minority group marginalization due to social class, race, ethnicity, nationality, gender, sexuality, age, ability, and religion remains an issue in American society. Language conventions impact not only popular understanding but the ways that scholars think and talk about social structure and social inequality. This is not just about fostering more positive interaction; it is about drawing attention to the relevance of history, social psychological processes of assigning and distilling meaning, and the ways that these processes structure social perceptions within the context of American society.

\section{References}

[1] Carson, C. (2001) The Autobiography of Martin Luther King, Jr. Warner Books, New York.

[2] Vail, M. (2006) The "Integrative" Rhetoric of Martin Luther King, Jr.'s "I Have a Dream" Speech. Rhetoric and Public Affairs, 9, 51-78. https://doi.org/10.1353/rap.2006.0032

[3] Inwood, J.F.J. (2009) Searching for the Promised Land: Examining Dr. Martin Luther King's Concept of the Beloved Community. Antipode, 41, 487-508. https://doi.org/10.1111/j.1467-8330.2009.00684.x

[4] Toennies, F. ([1887] 1957) Community and Society. Loomis, C., Trans., Harper, New York.

[5] Durkheim, E. ([1893] 1984) The Division of Labor in Society. Halls, W.D., Trans., The Free Press, New York. https://doi.org/10.1007/978-1-349-17729-5

[6] Bruhn, J.G. (2011) The Sociology of Community Connections. 2nd Edition, Springer, Netherlands. https://doi.org/10.1007/978-94-007-1633-9

[7] Brint, S. (2001) Gemeinschaft Revisited: A Critique and Reconstruction of the Community Concept. Sociological Theory, 19, 1-23. https://doi.org/10.1111/0735-2751.00125 
[8] Coleman, J. (1961) The Adolescent Society. Free Press, New York.

[9] Hillery, G. (1955) Definitions of Community: Areas of Agreement. Rural Sociology, 20, 111-123.

[10] Hillery Jr., G. (1968) Communal Organizations: A Study of Local Societies. University of Chicago Press, Chicago.

[11] Dewey, J. (1954) The Public and Its Problems. Henry Holt, New York.

[12] Dolber, B. (2011) From Socialism to "Sentiment": Toward a Political Economy of Communities, Counterpublics and Their Media through Jewish Working Class History. Communication Theory, 21, 90-109. https://doi.org/10.1111/j.1468-2885.2010.01377.x

[13] Miller, M. and Chamberlain, J. (2015) The Handbook of Community Sentiment. Springer, New York. https://doi.org/10.1007/978-1-4939-1899-7

[14] Foss, S. (1996) Rhetorical Criticism: Exploration and Practice. 2nd Edition, Waveland Press, Long Grove, IL.

[15] Zerubavel, E. (1991) Islands of Meaning. In: O'Brien, J., Ed., The Production of Reality: Essays and Readings on Social Interaction, 5th Edition, Pine Forge Press, Thousand Oaks, 11-27.

[16] Burke, K. (1969) A Grammar of Motives. University of California Press, Berkeley.

[17] Sandstrom, K., Lively, K., Martin, D. and Fine, G.A. (2014) Symbols, Selves and Social Reality: A Symbolic Interactionist Approach to Social Psychology and Sociology. 4th Edition, Oxford University Press, New York.

[18] Merriam-Webster Online Dictionary. http://www.merriam-webster.com/dictionary/community

[19] Parrillo, V. (2009) Strangers to These Shores: Race and Ethnic Relations in the United States. 9th Edition, Allyn and Bacon, Boston.

[20] Desmond, M. and Emirbayer, M. (2009) Racial Domination, Racial Progress: The Sociology of Race in America. McGraw-Hill, New York.

[21] Callero, P. (2013) The Myth of Individualism: How Social Forces Shape Our Lives. Rowman and Littlefield, Lanham, Maryland.

[22] Ryan, W. (1976) Blaming the Victim. Vintage, New York.

[23] Allport, G. and Postman, L. (1947) The Psychology of Rumor. Holt, Rinehart and Winston, New York.

[24] Schwalbe, M., Godwin, S., Holden, D., Schrock, D., Thompson, S. and Wolkomir, M. (2000) Generic Processes in the Reproduction of Inequality: An Interactionist Analysis. Social Forces, 79, 419-452. https://doi.org/10.2307/2675505

[25] Agba, R. and Nee, V. (2003) Remaking the American Mainstream: Assimilation and Contemporary Immigration. Harvard University Press, Cambridge.

[26] Baker, P. and Hotek, D. (2003) Perhaps a Blessing: Skills and Contributions of Recent Mexican Immigrants in the Rural Midwest. Hispanic Journal of Behavioral Sciences, 25, 448-468. https://doi.org/10.1177/0739986303259490

[27] Ogbu, J. (2004) Collective Identity and the Burden of 'Acting White': Black History, Community and Education. The Urban Review, 36, 1-35. https://doi.org/10.1023/B:URRE.0000042734.83194.f6

[28] Ogbu, J. (2008) Minority Status, Oppositional Culture and Schooling. Routledge, New York.

[29] Rumbaut, R. (2008) Reaping What You Sow: Immigration, Youth and Reactive Ethnicity. Applied Developmental Science, 12, 108-111. https://doi.org/10.1080/10888690801997341 
[30] Massey, D. and Sanchez, M. (2012) Brokered Boundaries: Creating Immigrant Identity in Anti-Immigrant Times. Russell Sage Foundation, New York.

[31] Celik, C. (2015) "Having a German Passport Will Not Make Me German": Reactive Ethnicity and Oppositional Identity Among Disadvantaged Male Turkish SecondGeneration Youth in Germany. Ethnic and Racial Studies, 38, 1646-1662. https://doi.org/10.1080/01419870.2015.1018298

[32] Massey, D. and Denton, N. (1993) American Apartheid: Segregation and the Making of the Underclass. Harvard University Press, Cambridge.

[33] Massey, D. (2001) Residential Segregation and Neighborhood Conditions in U.S. Metropolitan Areas. In: Smelser, N.J., Wilson, W.J. and Mitchell, F., Eds., America Becoming: Racial Trends and Consequences, National Academy Press, Washington, DC, 391-434.

[34] Bonilla-Silva, E., Goar, C. and Embrick, D. (2006) When Whites Flock Together: The Social Psychology of White Habitus. Critical Sociology, 32, 229-253. https://doi.org/10.1163/156916306777835268

[35] Payne, R. and Krabill, D. (2002) Hidden Rules of Class at Work. Aha! Process Inc, Highlands, TX.

[36] Lareau, A. (2011) Unequal Childhoods: Class, Race and Family Life. University of California Press, Los Angeles.

Submit or recommend next manuscript to SCIRP and we will provide best service for you:

Accepting pre-submission inquiries through Email, Facebook, LinkedIn, Twitter, etc. A wide selection of journals (inclusive of 9 subjects, more than 200 journals) Providing 24-hour high-quality service User-friendly online submission system Fair and swift peer-review system Efficient typesetting and proofreading procedure Display of the result of downloads and visits, as well as the number of cited articles Maximum dissemination of your research work

Submit your manuscript at: http://papersubmission.scirp.org/

Or contact jss@scirp.org 